\title{
Predation of artificial nests in UK farmland by magpies (Pica pica): interacting environmental, temporal, and social factors influence a nest's risk
}

\author{
Lucy A. Capstick ${ }^{1,2}$ (D) Rufus B. Sage ${ }^{2} \cdot$ Joah R. Madden $^{1}$ \\ Received: 22 November 2018 / Revised: 4 April 2019 / Accepted: 8 May 2019 /Published online: 26 May 2019 \\ (C) The Author(s) 2019
}

\begin{abstract}
The recent decline in farmland songbirds in the UK has coincided with increases in the populations of many nest predators. However, studies which have removed nest predators and monitored the response of prey populations have found mixed results. One explanation for this ambiguity is that, within species, predators differ in how likely they are to predate nests and only the removal of particularly predatory individuals will improve the breeding success of prey populations. Predators could differ in the extent to which they take nests due to variation in the local environment and/or variation within the predator population, e.g. differences in breeding status. Additional to these broad factors, certain individuals may specialise on particular prey. We placed 460 artificial nests in a systematically balanced design in UK farmland to analyse these sources of variation in predation. Magpies (Pica pica) were the most common predators of our artificial nests and the vulnerability of our nests to magpie predation varied according to magpie breeding status (predation was higher inside breeding magpies' territories), but this effect varied temporally. More nests were predated inside of magpie territories late in the season, when magpies had dependent fledglings. More specifically, some nest locations were especially vulnerable independent of both magpie breeding status and time in breeding season. These nests may have been disproportionately predated by specific, particularly predatory, territorial magpies. Habitat management and/or predator removal may benefit songbird populations if targeted towards reducing the effect of particular individuals identified as more likely to predate songbird nests.
\end{abstract}

Keywords Nest predation $\cdot$ Corvids $\cdot$ Songbirds $\cdot$ Farmland $\cdot$ Artificial nests $\cdot$ Pica pica

\section{Introduction}

Corvids, particularly magpies (Pica pica), have often been directly observed (Praus et al. 2014; Hanmer et al. 2017) or identified from physical evidence (Groom 1993; Chamberlain 1994) predating the eggs and chicks of UK songbirds in the nest. However, investigation at the regional and national population level has found little evidence of a causal link between increases in corvid populations and declines in songbird populations (Thomson et al. 1998; Newson et al. 2010). Meta-

Lucy A. Capstick

lcapstick@gwct.org.uk

1 Centre for Research in Animal Behaviour, Psychology, University of Exeter, Exeter EX4 4QG, UK

2 Game \& Wildlife Conservation Trust, Burgate Manor, Fordingbridge SP6 1EF, UK analyses of predator removal studies have not found a uniformly positive effect of corvid removal on songbird productivity or abundance (Holt et al. 2008; Madden et al. 2015). Nevertheless, some localised experimental studies have found increases in nest survival (White et al. 2014; Sage and Aebischer 2017), and subsequent growth in some songbird breeding populations (Stoate and Szczur 2006; Fletcher et al. 2010), following corvid removal. There are several possible explanations for this confused picture.

Firstly, corvids' conspicuous behaviour and diurnal activity may make them appear disproportionately responsible for nest predation, compared to more inconspicuous nocturnal predators such as rodents (Birkhead 1991). Corvids may simply not be common nest predators. Secondly, the eggs and chicks predated by corvids may be part of the population that would otherwise be lost due to different causes (compensatory mortality) (Errington 1946). In this case, increased corvid nest predation would not necessarily limit songbird population numbers. Thirdly, the breeding biology of some songbird 
species may render their nests more or less likely to be predated by corvids (Martin 1993) and although increased corvid numbers might affect susceptible species, this effect may be masked when studies consider population trends of multiple species. Finally, it may be that some individual corvids predate a disproportionate number of nests and if these particularly predatory individuals are not removed, songbird breeding success or population numbers do not increase.

Several factors may cause corvids to differ in how likely they are to predate songbird nests including variation in their external environment. For example, if the habitat that predators utilise (their home range) provides less concealment for nests, perhaps because hedges are severely cut and thin, predators may be more likely to detect and predate nests (Dunn et al. 2016).

Predators may also differ in their predation behaviour due to variation in internal factors. Predators which differ in their age, sex or breeding status may take different prey types (Dickman 1988; Sacks et al. 1999; Odden et al. 2002). Corvids such as magpies and crows (Corvus corone) can differ in breeding status. Their populations comprise of territorial breeding individuals as well as non-breeding itinerant individuals (Cramp and Perrins 1994). The breeding individuals defend a territory around their nest from intrusions by their predators and conspecifics during the breeding season. They also generally limit their foraging to within these territories (Birkhead 1991), possibly to facilitate this territorial defence (Martindale 1982). This restricted foraging area, and increased local habitat knowledge it facilitates, may cause territorial breeding corvids to encounter, and predate, more nests than non-breeding individuals which forage over a wider area (Møller 1988; Sálek 2004).

In addition to causing spatial variation in nest predation risk, these environmental and internal factors could also cause nest predation risk to vary temporally. The habitat is likely to change through the year. For instance, as vegetation grows, the protection from predation it provides may increase, dependent on the mix of plant species. Variation in internal factors, such as breeding status, may have a temporal effect on predators' likelihood to take particular prey. Breeding individuals may switch their prey preference in response to the nutritional needs of their young (Annett and Pierotti 1989). For example, predation of nests by corvids might be higher during particular stages of the corvids' own breeding season (Suvorov et al. 2012).

Alternatively, or in addition to these external and internal factors, predators may differ at an individual level in their propensity to predate nests (Woo et al. 2008). Although, at a population level corvids appear to have a generalist diet (Holyoak 1968), this could mask individual specialisation on different prey (Dickman and Newsome 2015). Some corvids may specialise on songbird eggs or chicks. Individuals may differ in their predation behaviour for a variety of reasons. If prey requires specific handling strategies and predators are limited in the number of strategies that they can learn, individuals may focus on different prey (Woo et al. 2008). Individuals may learn specific foraging preferences from their parents or others in their social group (Slagsvold and Wiebe 2011). Additionally, differences in personality have been shown to affect foraging preferences, for example bolder individuals may be more likely to dominate particular foraging habitats (Patrick and Weimerskirch 2014).

Farmland songbirds are a group of species in long-term population decline (DEFRA 2016). Identifying specific factors which cause corvids to differ in their predation of farmland songbird nests may demonstrate where predator and/or habitat management could be focused to achieve maximum increases in songbird productivity. More targeted conservation management is increasingly favoured due to economic and, in the case of predator removal, ethical concerns. If particular individuals or guilds of individuals disproportionately predate species of interest, independent of variation in the external environment, it may be possible to identify and selectively remove these 'problem individuals' (Swan et al. 2017). Alternatively, if external factors such as habitat variation drive differences in predation rates, prioritising the creation of habitat that is associated with reduced predation rates could be particularly beneficial.

We aimed to identify factors which caused variation in nest predation rates in a farmland environment using artificial nests. Specifically, we explored whether corvids were disproportionately responsible for predation, by monitoring the identity of nest predators using trail cameras and wax-filled eggs, which retain the beak or gnaw marks of the predators attempting to eat them (Bodey et al. 2009; Ludwig et al. 2012). We then explored whether spatial and temporal patterns of variation in predation could be explained by factors pertaining to the behaviour of local corvid predators. By presenting sets of artificial nests at different locations repeatedly throughout the breeding season, we could assess whether predation: (i) varied depending on predator breeding status, in this case whether predation was higher inside the territories of breeding magpies; (ii) varied temporally over the breeding season; (iii) varied within or between locations, specifically did predation differ between individual magpie territories; and (iv) varied due to habitat variation, measured as difference in hedge structure.

\section{Methods}

\section{Field site}

The study was carried out over $15 \mathrm{~km}^{2}$ of farmland in Warwickshire, England. This lowland area was dominated by farmland, with small fragments of deciduous and plantation woodland. The farmland was both arable and pastoral. The arable crops were mainly cereals, such as wheat (Triticum 
aestivum) and barley (Hordeum vulgare), and break crops, such as oil seed rape (Brassica napus) and field peas (Pisum sativum). The majority of the pastoral land was improved grassland grazed by sheep and cattle. Field size was relatively small ( $3.11 \pm 0.28 \mathrm{ha})$ and most fields were bordered by either managed (mechanically cut) or unmanaged hedgerows.

\section{Measurement of nest predation}

We constructed artificial nests from chicken wire lined and woven with hay and grass. These nests mimicked blackbird (Turdus merula) nests found on the field site in size, shape, and use of hay and grass. Nests were baited with one real quail's egg and one wax-filled quail's egg.

We presented artificial nests $(n=460)$ repeatedly at twentyfour selected hedgerow locations between 24 March 2016 and 26 July 2016. At each location, five artificial nests, each separated by $\sim 10 \mathrm{~m}$, were placed in realistic nest positions on a transect along the hedgerow. Each nest was exposed for 5 days and, to avoid alerting predators, nests were not visited during this time. Nests were considered predated if either egg was missing or damaged within the nest. Two methods of nest predator identification were used. Impressions left on the wax-filled eggs allowed us to broadly classify predators (categories used were medium-sized birds, small birds, small mammals and unknown). A subset of nests, approximately one third ( $n=151)$ were also monitored using trail cameras (Bushnell Trophy Camera HD) to allow more detailed identification of predators. Cameras were programmed to take 3 photographs ( 5 megapixel resolution) per trigger with a 1 -s trigger interval. The sensitivity of the passive infra-red sensor was set to "high" to maximise motion sensitivity. Predators were identified as animals seen at the nest interacting with nest contents. Cameras were positioned within the vegetation of the hedgerows to prevent them providing a visual indication of nest location. A randomly selected subset $(n=30)$ of the nests deployed were old, natural thrush nests, collected from the field site over winter, as oppose to wire nests constructed by us. This meant any effect of our use of man-made materials, as oppose to nesting materials used by birds, could be assessed.

\section{Assessing the effect of predator breeding status on nest predation}

Twelve (of twenty-four) locations where artificial nest transects were presented were situated within active magpie territories (magpie-present), and twelve were positioned at randomly selected sites where breeding magpies were absent (magpieabsent).

We identified the active magpie territories using a combination of methods. First, old magpie nest sites were located over the winter and early spring (before bud burst). This provided a likely territory centre, as nest sites were frequently reused (Birkhead 1991; LC personal observation). Second, we established that the territory was in use by locating the active nest site. Nest site use was confirmed by observing and recording locations of magpies in and around the nest site during the breeding season.

Active magpie nests in the best characterised area of the field site were found less than $200 \mathrm{~m}$ apart. Sites over $200 \mathrm{~m}$ from known magpie nest sites (even those believed to be inactive) were therefore defined as outside of magpie territories (magpieabsent). Areas which could not be visually searched for magpie nests (blocks of woodland over approx. 0.5 ha, and urban areas including gardens) were excluded from this experiment.

The transects in magpie-present locations were centred on the active magpie nest within the magpie territory; the first artificial nest of the transect was placed $\sim 10 \mathrm{~m}$ from the active magpie nest if the nest was in a hedgerow, or at the closest point on the nearest hedgerow ( $<25 \mathrm{~m}$ away) if the magpie nest was in a tree/copse. The transects in magpie absent locations were centred on randomly selected sites that matched magpie nest sites; the first artificial nest was placed at a random point on the hedgerow.

\section{Assessing the effect of temporal variation on nest predation}

Artificial nest transects were presented at the 24 locations in six blocks of four locations (two in magpie-present, two in magpie-absent locations). Nest transects were presented at each block, for 5 days each time, in April, May, June and July 2016. Nest transects were therefore presented at each block four times, except one block which was repeated three times due to logistical constraints, this meant 460 nests were presented in total.

To assess the relationship between temporal variation in nest predation rates and predator breeding phenology, magpie breeding was concurrently monitored on this field site (observations of active nests were made approximately every 4 days). Magpie young were found to fledge the nest between late-May and mid-June. This is comparable to regional estimates based on the BTO's Nest Record Scheme (Joys and Crick 2004).

\section{Assessing the effect of variation between individual predators on nest predation}

We aimed to identify individual variation in magpie predation behaviour by examining differences in recorded predation rates at each location. As members of the local magpie population were trapped and marked with colour rings we could identify individual territory owners; marked birds that were repeatedly observed or re-trapped near specific active nests were assumed to be the territory owners (Diaz-Ruiz et al. 
2010). By comparing the identity of the territory owners to the identity of colour ringed individuals observed predating nests within those territories (on trail camera photos) we could see if differences in predation rates between locations related to differences in predation by individual territorial magpies.

\section{Assessing the effect of habitat variation on nest predation}

Hedgerows at each nest location were crudely categorised as either open (above $2 \mathrm{~m}$, with an open structure, generally unmanaged and composed of a mix of tree/shrub species) or closed (below $2 \mathrm{~m}$ in height, narrow and dense and composed of hawthorn (Crataegus spp.) and blackthorn (Prunus spinosa)).

\section{Statistical analysis}

Firstly, we assessed the effect of aspects of the experimental design on predation rate (number of nests predated/ total number of nests). This was captured by three measures: the presence of cameras; the type of nest (man-made or made by birds); and the position of the nests along a transect (proximity to magpie nest). We assessed the effect of these measures on nest predation using chi-squared tests and found that predation did not significantly differ between nests with and without cameras $\left(\chi_{1}^{2}, n=460=2.54, p=0.11\right)$, between man-made nests or nests made by birds $\left(\chi_{1}{ }_{1}, n=460=0.94, p=0.33\right)$, or with nest position within a transect $\left(\chi_{1}^{2}, n=460=0.91, p=0.92\right)$.

We then used a generalised linear mixed modelling (GLMM) approach to assess the effect of the factors of interest (magpie presence, time in breeding season and habitat variation) on artificial nest transect predation. Inclusion of additional factors in these models led to model over-parametrisation and reduced model fit (Grueber et al. 2011; Thomas et al. 2015). Therefore, the factors related to experimental design (camera presence, man-made/made by birds, nest position within a transect), which were shown to have no effect on artificial nest predation, were excluded from these analyses.

We fitted proportion of nest transect predated (number of nests predated vs. number of nests not predated) as a binomial response in a GLMM with binomial error distribution and a logit-link function. Magpie territory presence (magpie-present vs. magpie-absent), time of nest transect presentation (date converted to a continuous numeric variable where day 1 corresponds to the first day artificial nests were presented, which was 24 March 2016), and hedge type (open/closed) were used as explanatory variables. To account for changes in habitat and magpie activity throughout the breeding season, the interaction terms date $\times$ magpie presence and date $\times$ hedge type were included. Artificial nest location was fitted as a random effect. We included location as a random effect to account for potential spatial autocorrelation between the repeated presentations of transects of nests at the same location and to explicitly examine differences in predation rates between locations, not accounted for by the fixed effects.

To examine if factors predicting predation rates differed depending on predator identity we initially fitted two maximal models; the first included all instances of predation (A) and the second included only predation attributed to medium-sized bird predators (B), effectively magpies (see "Results").

The significance of explanatory terms in both models was evaluated by removing variables one at a time and using chisquared tests to assess the change in model deviance (Crawley 2005). The first-order interaction terms were removed from models before the significance of fixed effects included in them was assessed (Crawley 2012; Fox et al. 2013). Nonsignificant interactions were excluded from minimal models, but all fixed effects were retained. The random effect (nest location) was tested using a likelihood ratio test of the maximal model, with and without the random effect (Westneat et al. 2014). Model assumptions were assessed using diagnostic plots (Thomas et al. 2015).

All analyses were carried out in R ver. 3.1.2 (R Core Team 2017). GLMMs were constructed using the lme4 package (Bates et al. 2014).

\section{Results}

\section{Predator identity}

Across all presentations of all artificial nest transects, 133 of the total 460 nests (28.9\%) were predated. Three guilds of nest predator were identified using either impressions left on wax eggs or trail camera photos or a combination of the two. The first of these, small birds (including songbirds), are not commonly known to be nest predators, but appeared to interact with artificial nest contents in a very small number of cases. The second guild of predators, small mammals, were identified as predators in $23.5 \%$ of cases where predators could be identified $(n=81)$ (Fig. 1). In cases where trail camera photos were available $(n=6)$, these small mammals were observed to be rodents, such as brown rats (Rattus norvegicus). No other mammals were observed predating nests on camera and although larger mammals, such as red foxes (Vulpes vulpes), were present on the field site, there was no evidence they predated the artificial nests. The third guild of nest predators, medium-sized birds, were by far the most frequently identified guild of nest predators (identified in $70.3 \%$ of cases where identification was possible $(n=81)$ ) (Fig. 1). Corvids were the only medium-sized birds observed predating nests on camera ( $48.5 \%$ of the 33 predated nests monitored by cameras). Of these corvids, $87.5 \%$ were magpies. There was 1 instance of jackdaw predation (Corvus monedula) and 1 of jay (Garrulus glandarius). We therefore assume that magpies were the major predators of our artificial nests. In cases where the wax- 
filled egg was removed from artificial nest or untouched, and there were no camera observations, we could not determine predator identity (Table 1). Camera observations suggested that neither mammals nor birds were more likely to leave eggs untouched or to remove them.

\section{Factors affecting artificial nest predation}

When predation by all predators was considered (model A) magpie presence did not influence predation rate. Time in the breeding season was significant, with predation rates generally declining over the breeding season (Table 2A). However, when we examined factors that predicted only predation by mediumsized birds, the results changed (model B). The effect of magpie presence on the proportion of nests predated by medium-sized birds varied temporally. Although overall approximately $75 \%$ more nests were predated in magpie-present locations, this disparity in predation rates between magpie-present and magpieabsent transects was only evident later in the breeding season. For example, in the last presentation of artificial nests (in early July), $20 \%$ of nests were predated by medium-sized birds in magpie-present locations, whereas none were predated in magpie-absent locations (Table 2B, Fig. 2).

In both models ( $\mathrm{A}$ and $\mathrm{B}$ ), the specific location of nest transects, which was fitted as a random effect, was also highly significant (Table 2). Accounting for the effect of the fixed factors (magpie presence, hedge type and time in the breeding season), predation rates, by all predators and by medium-sized birds only, differed between locations. For example, at some locations over $70 \%$ of artificial nests presented were predated whereas at other locations less than $10 \%$ of nests were predated (Fig. 3). We examined the identity of individual magpies observed on camera predating at specific locations, and

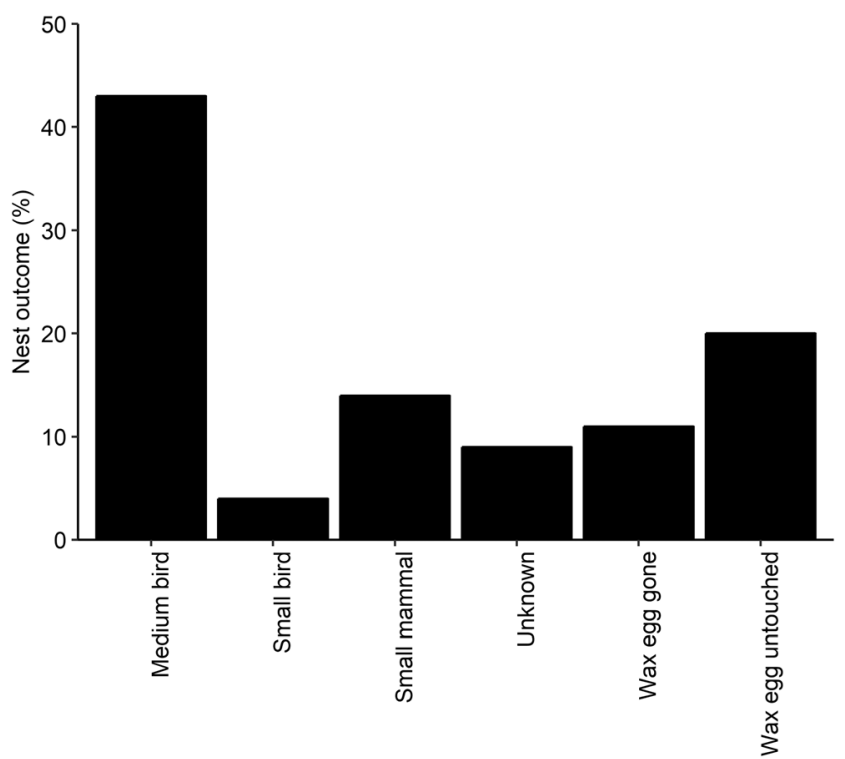

Fig. 1 Nest outcome for all predated artificial nests $(n=133)$ these observations indicated that higher predation at specific locations was driven by increased predation by local magpies. The individual colour-ringed magpies that were identified predating nest transects were only observed predating magpie-present transects located within their own territories, or in magpie-absent areas immediately adjacent to their territories. On the occasions when unringed birds were seen predating nests, the transects were in territories where the territory holders were not ringed.

\section{Discussion}

Almost $30 \%$ of artificial nests placed in hedgerows in UK farmland were predated and magpies were the most frequently identified predators. Several factors were found to affect the predation of the artificial nests, but the effect of these different factors was, at least partially, dependent on the identity of the nest predators. The probability of a nest being predated, by any predator, decreased over the course of the breeding season, as hedgerow vegetation became denser. However, when only nest predation by medium-sized birds (most likely magpies) was considered, there was a greater probability that nests placed in close proximity to active magpie nests were predated late in the breeding season (when magpies were provisioning fledglings). We also found evidence that nests placed in some territories were more likely to be predated regardless of environmental or temporal factors. Consequently, we suggest that the effect corvid predators have on songbird nests may vary due to differences in breeding status, time in the breeding season, and possibly due to additional differences in foraging behaviour or motivation between territory holders.

\section{Predation of artificial nests}

When predators of our artificial nests could be identified (using wax-filled eggs and/or trail camera photos), $70 \%$ of predation was attributed to medium-sized birds. The medium-sized bird nest predators present on the field site were limited to corvids (largely jackdaws, jays and magpies) and previous work suggests that magpies are the most likely of these to forage in farmland hedgerows (Angelstam 1986; Cramp et al. 1994). This was supported by our observations; $87 \%$ of the medium-sized birds identified on camera predating nests were magpies. Therefore, throughout this discussion we presume the majority of this medium-sized bird predation was due to magpies. One explanation for the disproportionately high predation by magpies we observed is that one of our methods of predator identification (using marks in wax-filled eggs) might lead to an underestimate of mammalian predation. Wax-filled eggs have an unnatural smell and may have been less attractive to mammals, which rely on olfactory cues to find prey, than to birds which tend to utilise visual cues 
Table 1 Count of the fate of predated artificial nests in magpie-absent $(n=60)$ and magpie-present $(n=73)$ transects (expressed as percentage of total predated nests in parenthesis)

\begin{tabular}{llccc}
\hline Nest outcome & & Magpie-absent & Magpie-present & Total \\
\hline Predator known & Small mammal & $8(6 \%)$ & $11(8 \%)$ & $19(14 \%)$ \\
& Small bird & $1(1 \%)$ & $4(3 \%)$ & $5(4 \%)$ \\
& Medium bird & $21(16 \%)$ & $36(27 \%)$ & $57(43 \%)$ \\
Predator unknown & Unknown & $5(4 \%)$ & $7(5 \%)$ & $12(9 \%)$ \\
& Wax-filled egg gone & $7(5 \%)$ & $7(5 \%)$ & $14(11 \%)$ \\
& Wax-filled egg untouched & $18(14 \%)$ & $8(6 \%)$ & $26(20 \%)$ \\
Total & & $60(45 \%)$ & $73(55 \%)$ & $133(100 \%)$ \\
\hline
\end{tabular}

(Rangen et al. 2000). However, it did not appear that mammalian predators were taking real eggs and leaving wax-filled eggs untouched. Marks in our wax-filled eggs revealed that they were attacked by various mammalian predators and in the minority of predated nests where wax-filled eggs were untouched we rarely found evidence which suggested that the real eggs had been taken by mammals, such as shell fragments left in the nest (Best 1978; Marini and Melo 1998).

We are therefore confident that we have correctly classified the predators of our artificial nests. However, we could not directly assess whether the spatial and temporal patterns of predation observed, and the nest predators identified, were representative of natural nests in the same environment (Wilson et al. 1998; Pärt and Wretenberg 2002). For example, in the case of the latter, it has been suggested that small birds do not predate natural nests as frequently as they predate artificial nests as they are often deterred from natural nests by the breeding pair (Zanette 2002). It is also possible that the presence of researchers around artificial nest sites attracted particular predator species (Major 1990; Major and Kendal 1996), especially visually orientated avian predators (Westmoreland and Best 1985; Götmark 1992). Corvids particularly can learn to associate individual humans with specific actions (Lee et al. 2011); in this study, some magpies may have formed an association between the researcher and the presence of artificial nests (Götmark et al. 1990; Strang 1980). Conversely, other research has shown that human visitation of nests does not influence predation rates (Fletcher et al. 2005; Lambert and Kleindorfer 2006), and even that corvids can be deterred by human observers (Götmark and Ahlund 1984). In this particular case, any association between the researcher and artificial nests may have been weakened as the researcher was regularly present on the field site and interacting with the habitat for reasons unrelated to the positioning of artificial nests.

Table 2 Models showing the factors causing variation in the rate of artificial nest predation by (A) all predators and (B) medium-sized birds. Nonsignificant interaction terms are not shown

(A)

Fixed effects

Intercept (magpie presence-absence, hedge-open)

Hedge type

Date

Magpie presence

Random effects

Location

(B)

Fixed effects

Intercept (magpie presence-absence, hedge-open)

Hedge type

Date

Magpie presence

Magpie presence $\times$ date

Random effects

Location

*Significant results $(p<0.05)$

$\begin{array}{lllll}\text { Estimate }(\beta) & \text { SE } & \text { Test statistic }\left(\chi^{2}\right) & d f & P \text { value } \\ 0.41 & 0.75 & & & \\ -1.20 & 0.66 & 3.24 & 1 & 0.072 \\ -0.01 & <0.01 & 5.18 & 1 & 0.023^{*} \\ -0.34 & 0.6 & 0.32 & 1 & 0.569 \\ & & & & \\ \text { Estimate }\left(\sigma^{2}\right) & \text { SE } & \text { Test statistic }\left(\chi^{2}\right) & d f & P \text { value } \\ 1.30 & 0.26 & 53.46 & 1 & <0.001^{*}\end{array}$

\begin{tabular}{lllll} 
Estimate $(\beta)$ & SE & Test statistic $\left(\chi^{2}\right)$ & $d f$ & $P$ value \\
-1.25 & 0.99 & & & \\
-1.25 & 0.80 & 2.33 & 1 & 0.127 \\
-1.49 & 1.03 & $<0.01$ & 1 & 0.984 \\
-0.01 & 0.01 & 0.87 & 1 & 0.351 \\
0.02 & 0.01 & 4.84 & 1 & $0.028^{*}$ \\
Estimate $\left(\sigma^{2}\right)$ & SE & Test statistic $\left(\chi^{2}\right)$ & $d f$ & $P$ value \\
1.67 & 0.34 & 28.42 & 1 & $<0.001^{*}$ \\
\hline
\end{tabular}




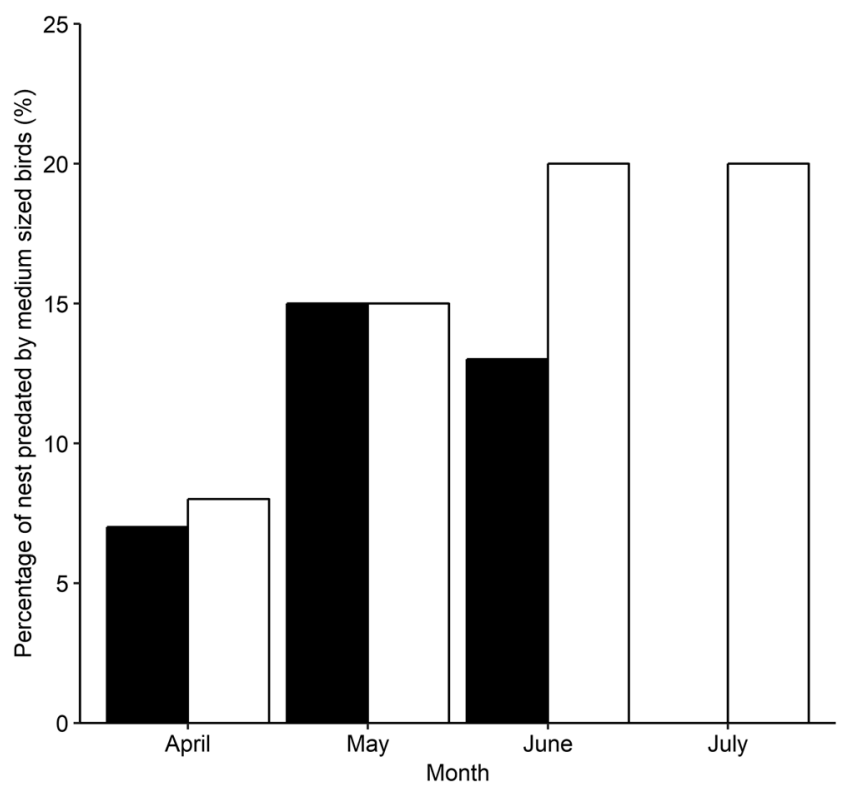

Fig. 2 Percentage of nests predated by medium-sized birds in magpiepresent (white bars) and magpie-absent (black bars) locations for each month

Natural songbird nests were monitored on the field site concurrent to this study, but the sample size was relatively small, and we could not identify the specific nest predators responsible as using the remains of natural nests to identify nest predators has been shown to be unreliable (Lariviere 1999; Mallord et al. 2012). Nonetheless, the natural songbird nests monitored were also found to suffer high rates of predation and the high proportion of avian predation suffered by our artificial nests is comparable to that observed in studies of natural nests in similar environments (Chamberlain 1994; Hatchwell et al. 1996). Artificial nests can experience patterns of nest predation comparable with coexisting natural nests, particularly when an attempt is made to mimic natural eggs and nests (Roos 2002; Pehlak and Lohmus 2008). The nests we constructed were modelled on thrush nests found on the study site and did not differ in predation rates compared to old thrush nests when both were baited with quail's eggs. We therefore suggest that the predation of our artificial nests can provide insight into variation in nest predation and nest predator behaviour if not a direct representation of natural nest predation.

\section{Effect of magpie presence on nest predation}

Nest predation by all predators varied temporally; the rate of predation attributed to all predators declined towards the end of the breeding season, probably because nests became increasingly concealed due to growth in hedgerow vegetation (Söderström 2001; Rodewald et al. 2009). Predation by magpies on nests placed further from active magpie nests (outside of magpie territories) also showed the same trend, suggesting predation by non-territorial magpies (identified on the field site as part of an ongoing trapping program) may also have been reduced when foliage was denser.

However, predation specifically by magpies within magpie territories did not decline over the course of the breeding season despite equivalent vegetation growth. Territorial magpies have a more restricted foraging range than non-territorial birds (Vines 1981). They may therefore more thoroughly and frequently explore their foraging range (Møller 1988) and thus continue to encounter songbird nests within it even when nests are harder to find. Factors other than variation in habitat use may also have caused nests in areas used by breeding magpies to be relatively more vulnerable late in the breeding season. Magpies provision their young within their territory for at least 4 weeks after fledging (Birkhead 1991); therefore (considering magpie fledging

Fig. 3 Average percentage of nest transects predated per presentation $\pm 1 \mathrm{SE}$ at magpiepresent (white bars) and magpieabsent (black bars) sites

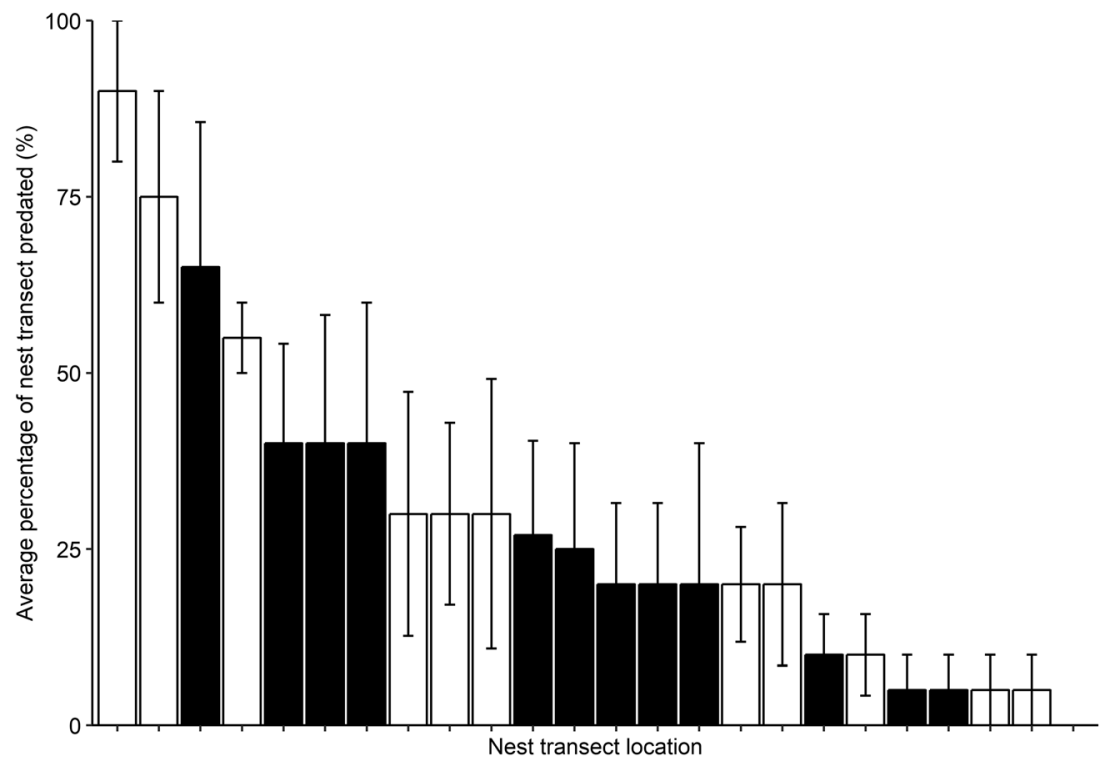


dates on this site), it is likely magpies were feeding dependent fledglings during this period. When provisioning their young magpies, like other bird species (Sasvari and Hegyi 1998; Davoren and Burger 1999), may preferentially seek out protein-rich prey such as eggs which could benefit the developing fledglings (Annett and Pierotti 1989).

Nonetheless, this apparent difference in magpie predation between magpie-present and magpie-absent sites did not affect overall survival of artificial nests. Although predation was still elevated at magpie-present sites, when predation by predators other than magpies was included in the analysis, the difference was not significant. This might suggest that other predators compensated, at least partially, for any differences in magpie nest predation (Ellis-Felege et al. 2012).

\section{Effect of location on artificial nest predation}

Although nests placed in spatial association with an active magpie nest did suffer increased nest predation rates by magpies, not all nest transects placed in magpie territories suffered high predation. When considering either all predation or only predation by magpies, there was variation between locations, independent of magpie nest presence. Some artificial nest transects directly under active magpie nests were not heavily predated. Conversely, some transects identified as having higher predation rates were not adjacent to magpie nests. The latter case may indicate that non-territorial magpies were significant nest predators at some locations throughout the breeding season. However, non-territorial magpies are ephemeral in any particular area (Birkhead 1991) and are unlikely to be responsible for the consistently high nest predation observed at specific locations over four separate presentations of the artificial nests. Breeding territorial corvids may forage further from their nests to exploit particular, sparse, resources (Neatherlin and Marzluff 2004), and it seems more likely that the magpie-absent transects which had higher predation rates were within the foraging range of a nearby breeding magpie pair. The predatory individuals that could be identified on camera were all part of the neighbouring breeding pair adjacent to the magpie-absent transect.

However, this does not explain why we did not observe high predation rates on some magpie-present transects. Some territorial magpies did not repeatedly predate songbird nests around their own nest, even late in the breeding season when magpie predation of nests in magpie-present transects was highest. Individual predators within a population have been shown to differ in their foraging behaviour, both in prey choice and foraging location (Graham et al. 2011; Patrick and Weimerskirch 2014). Territorial magpies may have differed, at an individual level, in the extent to which they engaged in nest predation. Our experimental design, in which nests were repeatedly placed in the same location, may have emphasised any differences between territory holders. Corvids, including magpies, are able to remember and re-visit specific feeding locations (Sonerud and Fjeld 1987; Birkhead 1991; Zinkivskay et al. 2009). It may have been that individuals which encountered and predated nests early in breeding season may have developed a search image for our artificial nests and this experience could have facilitated relatively increased rates of nest predation later in the breeding season (Møller 1988; Vigallon et al. 2005). Further research would be required to understand if and why particular magpies are more likely to predate eggs and to provide a mechanism by which these individuals could be characterised.

Critically, as the data included in our analysis were collected in only 1 year and at one site, we cannot be certain that the higher predation rates observed in certain locations were because particularly predatory individuals held those territories, rather than because of some inherent property of those territories (for example the presence of a specific habitat characteristic) that we did not consider. Alternatively, perhaps there was some interaction between the properties of a territory and the behaviour of the territory holders such that the owners of particular territories were more likely to predate nests within them. For example, the owners of the best quality territories may be dominant older birds (Birkhead 1991) which also be more experienced predators.

Further fine-scale multi-year analysis relating magpie territory ownership to nest predation rates within those territories would be necessary to disentangle the relative influence of habitat variation between territories and magpie identity. In any case, identifying either territory holders or territories which are associated with an increased risk of songbird nest predation may indicate where management of predators and/ or habitat could be targeted (Swan et al. 2017).

\section{Implications of findings}

Further work relating the patterns of artificial nest predation we found to the survival of natural nests would provide additional support for the application of our findings to management (Burke et al. 2004). Nonetheless, considering the effect of the factors found to explain variation in the likelihood of artificial nests being predated in this study could facilitate the identification of natural nests most susceptible to predation. Targeting management specifically towards improving the survival of these vulnerable nests may be more likely to increase the overall productivity of threatened songbird populations.

Targeted management could include improving nesting habitat in areas where predators are likely to take nests. For example, by increasing the protection provided by nest vegetation near to magpie nests (where nests were relatively more vulnerable late in the breeding season) (Dunn et al. 2016). Additionally, if we can identify the states or personality of individuals especially likely to predate songbird nests and directly target these individuals for removal or behavioural 
change (e.g. through diversionary feeding (Redpath et al. 2001)), then we might expect there to be greater benefits from control and management strategies (Blackwell et al. 2016; Swan et al. 2017). However, the consequences of removing particularly predatory individuals should be carefully considered. In our study, we could not distinguish whether the elevated predation risk was associated with territory holders, their specific territories or a combination of the two. It may be that removal of magpies from territories where predation rates are high would lead to other magpies replacing them and engaging in equally high rates of nest predation.

Furthermore, although magpies were identified as major nest predators in this study, the role of other predator species should also be considered. We found evidence that other predators compensated, at least partially, for differences in the rates magpie nest predation. Any management strategy aimed at improving bird breeding success should take into account the effect of the predator community as a whole.

Acknowledgements We thank the farmers who allowed us to use their land for this study. We thank Chloe Stevens, Tim Fawcett, Tim Birkhead, Lauren Brent and two anonymous reviewers for providing comments on earlier drafts of the manuscript. We also thank Nicholas Aebischer for providing statistical advice.

Funding This work was funded by the SongBird Survival and the University of Exeter as an industry partnership studentship.

\section{Compliance with ethical standards}

Between May 2014 and July 2016, 101 magpies were trapped and ringed with colour rings. Magpies were re-trapped on 205 occasions. All magpie trapping and colour ringing followed best practice guidelines of Natural England and the Game \& Wildlife Conservation Trust, and was carried out under Natural England licence 2016-19794-SCI-SCI.

Conflict of interest The authors declare that they have no conflict of interest.

Open Access This article is distributed under the terms of the Creative Commons Attribution 4.0 International License (http:// creativecommons.org/licenses/by/4.0/), which permits unrestricted use, distribution, and reproduction in any medium, provided you give appropriate credit to the original author(s) and the source, provide a link to the Creative Commons license, and indicate if changes were made.

\section{References}

Angelstam P (1986) Predation on ground-nesting birds' nests in relation to predator densities and habitat edge. Oikos 47:365-373. https:// doi.org/10.2307/3565450

Annett C, Pierotti R (1989) Chick hatching as a trigger for dietary switching in the western gull. Colon Waterbirds 12:4-11. https:// doi.org/10.2307/1521306

Bates D, Maechler M, Bolker B, Walker S (2014) Fitting linear mixedeffects models using lme4. J Stat Softw 67:1-48. https://doi.org/10. 18637/jss.v067.i01
Best L (1978) Field sparrow reproductive success and nesting ecology. Auk 95:9-22

Birkhead TR (1991) The magpies: the ecology and behaviour of blackbilled and yellow-billed magpies. T \& AD Poyser, London

Blackwell BF, DeVault TL, Fernandez-Juricic E et al (2016) No single solution: application of behavioural principles in mitigating humanwildlife conflict. Anim Behav 120:245-254. https://doi.org/10. 1016/j.anbehav.2016.07.013

Bodey TW, McDonald RA, Bearhop S (2009) Mesopredators constrain a top predator: competitive release of ravens after culling crows. Biol Lett 5:617-620. https://doi.org/10.1098/rsbl.2009.0373

Burke DM, Elliott K, Moore L et al (2004) Patterns of nest predation on artificial and natural nests in forests. Conserv Biol 18:381-388. https://doi.org/10.1111/j.1523-1739.2004.00014.x

Chamberlain D (1994) The factors affecting reproductive success and breeding density in a rural population of blackbirds, Turdus merula $L$. University of Oxford, Oxford

Cramp S, Perrins CM (1994) Handbook of the birds of Europe, the Middle East and North Africa. The birds of the Western Palearctic, vol 9: buntings and new world warblers. Oxford University Press, Oxford

Cramp S, Perrins C, Brooks D (1994) Handbook of the birds of Europe, the Middle East, and North Africa: the birds of the western Palearctic, vol. 8: Crows to finches. Oxford University Press, Oxford

Crawley MJ (2005) Statistics: an introduction using R. Wiley, Chichester

Crawley MJ (2012) The R book. Wiley-Blackwell, Chichester

Davoren GK, Burger AE (1999) Differences in prey selection and behaviour during self-feeding and chick provisioning in rhinoceros auklets. Anim Behav 58:853-863. https://doi.org/10.1006/anbe.1999.1209

DEFRA (2016) UK biodiversity indicators 2015: measuring progress towards halting biodiversity loss. DEFRA, London

Diaz-Ruiz F, Garcia JT, Perez-Rodriguez L et al (2010) Experimental evaluation of live cage-traps for black-billed magpies Pica pica management in Spain. Eur J Wildl Res 56:239-248. https://doi.org/10. 1007/s10344-009-0310-3

Dickman CR (1988) Age-related dietary change in the European hedgehog, Erinaceus europaeus. J Zool 215:1-14. https://doi.org/10. 1111/j.1469-7998.1988.tb04881.x

Dickman CR, Newsome TM (2015) Individual hunting behaviour and prey specialisation in the house cat Felis catus: implications for conservation and management. Appl Anim Behav Sci 173:76-87. https://doi.org/10.1016/j.applanim.2014.09.021

Dunn JC, Gruar D, Stoate C, Szczur J, Peach WJ (2016) Can hedgerow management mitigate the impacts of predation on songbird nest survival? J Environ Manag 184:535-544. https://doi.org/10.1016/j. jenvman.2016.10.028

Ellis-Felege SN, Conroy MJ, Palmer WE, Carroll JP (2012) Predator reduction results in compensatory shifts in losses of avian ground nests. J Appl Ecol 49:661-669. https://doi.org/10.1111/j.1365-2664. 2012.02126.x

Errington BYPL (1946) Predation and vertebrate populations. Q Rev Biol 21:144-177

Fletcher K, Warren P, Baines D (2005) Impact of nest visits by human observers on hatching success in lapwings Vanellus vanellus: a field experiment. Bird Study 52:221-223. https://doi.org/10.1080/ 00063650509461395

Fletcher K, Aebischer NJ, Baines D, Foster R, Hoodless AN (2010) Changes in breeding success and abundance of ground-nesting moorland birds in relation to the experimental deployment of legal predator control. J Appl Ecol 47:263-272. https://doi.org/10.1111/j. 1365-2664.2010.01793.x

Fox GA, Negrete-Yankelevich S, Sosa VJ (2013) Ecological statistics: contemporary theory and application. Oxford University Press, Oxford

Götmark F (1992) The effects of investigator disturbance on nesting birds. In: Current ornithology. Springer, Boston, pp 63-104 
Götmark F, Ahlund M (1984) Do field observers attract nest predators and influence nesting success of common eiders? J Wildl Manag 48: 381. https://doi.org/10.2307/3801169

Götmark F, Neergaard R, Ahlund M (1990) Predation of artificial and real arctic loon nests in Sweden. J Wildl Manag 54:429. https://doi.org/ $10.2307 / 3809653$

Graham IM, Harris RN, Matejusová I, Middlemas SJ (2011) Do 'rogue' seals exist? Implications for seal conservation in the UK. Anim Conserv 14:587-598. https://doi.org/10.1111/j.1469-1795.2011. 00469.x

Groom DW (1993) Magpie Pica-pica predation on blackbird Turdusmerula nests in urban areas. Bird Study 40:55-62. https://doi.org/ $10.1080 / 00063659309477129$

Grueber CE, Nakagawa S, Laws RJ, Jamieson IG (2011) Multimodel inference in ecology and evolution: challenges and solutions. J Evol Biol 24:699-711. https://doi.org/10.1111/j.1420-9101.2010.02210.x

Hanmer HJ, Thomas RL, Fellowes MDE (2017) Provision of supplementary food for wild birds may increase the risk of local nest predation. Ibis (Lond 1859) 159:158-167. https://doi.org/10.1111/ibi.12432

Hatchwell BJ, Chamberlain DE, Perrins CM (1996) The reproductive success of blackbirds Turdus merula in relation to habitat structure and choice of nest site. Ibis (Lond 1859) 138:256-262. https://doi. org/10.1111/j.1474-919X.1996.tb04337.x

Holt AR, Davies ZG, Tyler C, Staddon S (2008) Meta-analysis of the effects of predation on animal prey abundance: evidence from UK vertebrates. PLoS One 3:e2400. https://doi.org/10.1371/journal. pone. 0002400

Holyoak D (1968) A comparative study of the food of some British corvidae. Bird Study 15:147-153. https://doi.org/10.1080/ 00063656809476194

Joys AC, Crick HQP (2004) Breeding periods for selected bird species in England. British Trust for Ornithology, Thetford

Lambert S, Kleindorfer S (2006) Nest concealment but not human visitation predicts predation of New Holland honeyeater nests. Emu 106:63-68. https://doi.org/10.1071/MU05006

Lariviere S (1999) Reasons why predators cannot be inferred from nest remains. Condor 101:718-721. https://doi.org/10.2307/1370209

Lee WY, Lee SI, Choe JC, Jablonski PG (2011) Wild birds recognize individual humans: experiments on magpies, Pica pica. Anim Cogn 14:817-825. https://doi.org/10.1007/s10071-011-0415-4

Ludwig M, Schlinkert H, Holzschuh A, Fischer C, Scherber C, Trnka A, Tscharntke T, Batáry P (2012) Landscape-moderated bird nest predation in hedges and forest edges. Acta Oecol 45:50-56. https://doi. org/10.1016/j.actao.2012.08.008

Madden C, Arroyo B, Amar A (2015) A review of the impacts of corvids on bird productivity and abundance. Ibis (Lond 1859) 157:1-16

Major RE (1990) The effect of human observers on the intensity of nest predation. Ibis (Lond 1859) 132:608-612

Major RE, Kendal CE (1996) The contribution of artificial nest experiments to understanding avian reproductive success: a review of methods and conclusions. Ibis (Lond 1859) 138:298-307. https:// doi.org/10.1111/j.1474-919x.1996.tb04342.x

Mallord JW, Orsman CJ, Cristinacce A, Butcher N, Stowe TJ, Charman EC (2012) Mortality of wood warbler Phylloscopus sibilatrix nests in Welsh oakwoods: predation rates and the identification of nest predators using miniature nest cameras. Bird Study 59:286-295. https://doi.org/10.1080/00063657.2012.669359

Marini M, Melo C (1998) Predators of quail eggs, and the evidence of the remains: implications for nest predation studies. Condor 100:395-399

Martin TE (1993) Nest predation and nest sites. Bioscience 43:523-532

Martindale S (1982) Nest defense and central place foraging: a model and experiment. Behav Ecol Sociobiol 10:85-89. https://doi.org/10. 1007/BF00300167

Møller AP (1988) Nest predation and nest site choice in passerine birds in habitat patches of different size: a study of magpies and blackbirds. Oikos 53:215-221
Neatherlin E, Marzluff J (2004) Responses of American crow populations to campgrounds in remote native forest landscapes. J Wildl Manag 68:708-718

Newson SE, Leech DI, Hewson CM, Crick HQP, Grice PV (2010) Potential impact of grey squirrels Sciurus carolinensis on woodland bird populations in England. J Ornithol 151:211-218. https://doi. org/10.1007/s10336-009-0445-8

Odden J, Linnell JDC, Moa PF, Herfindal I, Kvam T, Andersen R (2002) Lynx depredation on domestic sheep in Norway. J Wildl Manag 66: $98-105$

Pärt T, Wretenberg J (2002) Do artificial nests reveal relative nest predation risk for real nests? J Avian Biol 33:39-46. https://doi.org/10. 1034/j.1600-048X.2002.330107.x

Patrick SC, Weimerskirch H (2014) Personality, foraging and fitness consequences in a long lived seabird. PLoS One 9:e87269. https://doi. org/10.1371/journal.pone.0087269

Pehlak H, Lohmus A (2008) An artificial nest experiment indicates equal nesting success of waders in coastal meadows and mires. Ornis Fenn 85:66-71

Praus L, Hegemann A, Tieleman BI, Weidinger K (2014) Predators and predation rates of skylark Alauda arvensis and woodlark Lullula arborea nests in a semi-natural area in The Netherlands. Ardea 102:87-94

R Core Team (2017) R: A language and environment for statistical computing. R Foundation for Statistical Computing, Vienna

Rangen S, Clark R, Hobson K (2000) Visual and olfactory attributes of artificial nests. Auk 117:136-146

Redpath SM, Thirgood SJ, Leckie FM (2001) Does supplementary feeding reduce predation of red grouse by hen harriers? J Appl Ecol 38: 1157-1168. https://doi.org/10.1046/j.0021-8901.2001.00683.x

Rodewald AD, Shustack DP, Hitchcock LE (2009) Exotic shrubs as ephemeral ecological traps for nesting birds. Biol Invasions 12:3339. https://doi.org/10.1007/s10530-009-9426-3

Roos S (2002) Functional response, seasonal decline and landscape differences in nest predation risk. Oecologia 133:608-615. https://doi. org/10.1007/s00442-002-1056-8

Sacks BN, Neale JCC, McCullough DR, Jaeger MM (1999) Territoriality and breeding status of coyotes relative to sheep predation. J Wildl Manag 63:593-605. https://doi.org/10.2307/3802648

Sage RB, Aebischer NJ (2017) Does best-practice crow Corvus corone and magpie Pica pica control on UK farmland improve nest success in hedgerow-nesting songbirds? A field experiment. Wildl Biol 17: wlb.00375. https://doi.org/10.2981/wlb.00375

Sálek M (2004) The spatial pattern of the black-billed magpie, Pica pica, contribution to predation risk on dummy nests. Folia Zool 53:57-64

Sasvari L, Hegyi Z (1998) Bird predation by tawny owls (Strix aluco L.) and its effect on the reproductive performance of tits. Acta Oecol 19: 483-490. https://doi.org/10.1016/s1146-609x(99)80002-2

Slagsvold T, Wiebe KL (2011) Social learning in birds and its role in shaping a foraging niche. Philos Trans R Soc B Biol Sci 366:969977. https://doi.org/10.1098/rstb.2010.0343

Söderström B (2001) Seasonal change in red-backed shrike Lanius collurio territory quality - the role of nest predation. Ibis (Lond 1859) 143:561-571. https://doi.org/10.1111/j.1474-919X.2001. tb04883.x

Sonerud G, Fjeld P (1987) Long-term memory in egg predators: an experiment with a hooded crow. Ornis Scand 18:323-325

Stoate C, Szczur J (2006) Potential influence of habitat and predation on local breeding success and population in spotted flycatchers Muscicapa striata. Bird Study 53:328-330. https://doi.org/10. 1080/00063650609461450

Strang CA (1980) Incidence of avian predators near people searching for waterfowl nests. J Wildl Manag 44:220. https://doi.org/10.2307/ 3808372

Suvorov P, Svobodova J, Koubova M, Dohnalova L (2012) Ground nest depredation by European black-billed magpies Pica pica: an 
experimental study with artificial nests. Acta Ornithol 47:55-61. https://doi.org/10.3161/000164512x653926

Swan GJF, Redpath SM, Bearhop S, McDonald RA (2017) Ecology of problem individuals and the efficacy of selective wildlife management. Trends Ecol Evol 32:518-530. https://doi.org/10.1016/j.tree. 2017.03.011

Thomas R, Vaughan I, Lello J (2015) Data analysis with R statistical software: a guidebook for scientists. Eco-explore

Thomson DL, Green RE, Gregory RD, Baillie SR (1998) The widespread declines of songbirds in rural Britain do not correlate with the spread of their avian predators. Proc R Soc B Biol Sci 265:2057-2062. https://doi.org/10.1098/rspb.1998.0540

Vigallon S, Marzluff J, Burger A (2005) Is nest predation by Steller's Jays (Cyanocitta stelleri) incidental or the result of a specialized search strategy? Auk 122:36-49

Vines G (1981) A socio-ecology of magpies. Ibis (Lond 1859) 123:190202. https://doi.org/10.1111/j.1474-919X.1981.tb00924.x

Westmoreland D, Best LB (1985) The effect of disturbance on mourning dove nesting success. Auk 774:780

Westneat DF, Bókony V, Burke T, Chastel O, Jensen H, Kvalnes T, Lendvai ÁZ, Liker A, Mock D, Schroeder J, Schwagmeyer PL, Sorci G, Stewart IRK (2014) Multiple aspects of plasticity in clutch size vary among populations of a globally distributed songbird. J Anim Ecol 83:876-887. https://doi.org/10.1111/1365-2656.12191
White P, Stoate C, Szczur J, Norris K (2014) Predator reduction with habitat management can improve songbird nest success. J Wildl Manag 78:402-412. https://doi.org/10.1002/jwmg.687

Wilson G, Brittingham M, Goodrich L (1998) How well do artificial nests estimate success of real nests? Condor 100:357-364

Woo KJ, Elliott KH, Davidson M, Gaston AJ, Davoren GK (2008) Individual specialization in diet by a generalist marine predator reflects specialization in foraging behaviour. J Anim Ecol 77:10821091. https://doi.org/10.1111/j.1365-2656.2008.01429.x

Zanette L (2002) What do artificial nests tells us about nest predation? Biol Conserv 103:323-329

Zinkivskay A, Nazir F, Smulders TV (2009) What-where-when memory in magpies (Pica pica). Anim Cogn 12:119-125. https://doi.org/10. 1007/s10071-008-0176-x

Publisher's note Springer Nature remains neutral with regard to jurisdictional claims in published maps and institutional affiliations. 